We confirm the importance of short response times, and they should be reduced further when more staff are available. About half of the patients received some resuscitation from bystanders despite a shortage of formal training of the public.

Without the availability of rapid defibrillation resuscitation by bystanders will be only of limited value. The introduction of semiautomatic, advisory defibrillators for non-extended trained crews should reduce the time to defibrillation and make this procedure available to more people. ${ }^{5}$ This combination of extended and non-extended trained crews may prove most effective.

This study was made possible by the work of many members of the ambulance service and the extended training advisory group.

1 Mackintosh AF, Crabb ME, Grainger R, Williams JH, Chamberlain DA. The Brighton resuscitation ambulances: review of 40 consecutive survivors of outof-hospital cardiac arrest. $\mathrm{Br} \mathrm{Med} \mathcal{F} 1978$;i:1115-8.

2 Eisenberg MS, Copass MK, Hallstrom AP, et al. Treatment of out-of-hospital cardiac arrests with rapid defibrillation by emergency medical technicians. $N$ Engl f Med 1980;302:1379-83.

3 Ambulance Staff Training Committee. Extended training in ambulance aid. Bristol: NHS Training Authority, 1987.

4 Weaver WD, Cobb LA, Hallstrom AP, Fahrenbruch C, Copass MK, Ray R. Factors influencing survival after out-of-hospital cardiac arrest. $\mathcal{f} \mathrm{Am} \mathrm{Coll}$ Cardiol 1986;7:752-7.

5 Weaver WD, Copass MK, Hill DL, Fahrenbruch C, Hallstrom AP, Cobb LA Cardiac arrest treated with a new automatic external defibrillator by out-of hospital first responders. Am $\mathcal{F}$ Cardiol 1986;57:1017-21.

(Accepted 7 April 1989)

\section{Cost minimisation study of transdermal glyceryl trinitrate in reducing failures of peripheral intravenous infusion}

\section{H T Khawaja, B J O'Brien, M J Buxton, P C Weaver}

Department of Surgery, St Mary's Hospital,

Portsmouth PO3 6AD

H T Khawaja, FRCS, research fellow

PC Weaver, FRCS, consultant surgeon

\section{Health Economics}

Research Group, Brunel

University, Uxbridge,

Middlesex UB8 3PH

B J O'Brien, MSC, research

fellow

M J Buxton, BA, senior

research fellow

Correspondence to: $\mathrm{Mr}$ Khawaja.

BrMed f 1989;299:97

Phlebitis and extravasation are common causes of failure of peripheral intravenous infusion. ${ }^{12}$ Such failures result in discomfort to patients and reinfusion not only incurs extra costs but takes up staff time. Recent clinical trials showed that prophylactic use of transdermal glyceryl trinitrate reduced the incidence of phlebitis and infusion failure. ${ }^{3+}$ We assessed the effect on hospital resources when this method was used.

\section{Methods and results}

Data were obtained from an earlier trial on 340 consecutive patients requiring infusions in a general surgical ward. The patients were randomised to treatment with a self adhesive glyceryl trinitrate patch or an identical placebo patch; the patches for both groups were changed daily. The earlier study showed that using glyceryl trinitrate patches delayed failure of the
Expected costs of using glyceryl trinitrate patches to delay failure of peripheral intravenous infusion infusion from 74 hours in the control group to 127 hours. ${ }^{4}$

Our evaluation used the method of cost minimisation $^{5}$ and assessed the net impact that patch treatment had on hospital resources. The expected cost of an infusion to time $t$ was the sum of the initial cost, the cost of changing the patch daily, and the cost of reinfusion weighted by the cumulative probability of failure to time $t$. We calculated the expected costs for the treatment and control groups. The costs of patches, cannulas, giving sets, and infusion fluids were taken as the prices that the hospital paid, net of discount. The

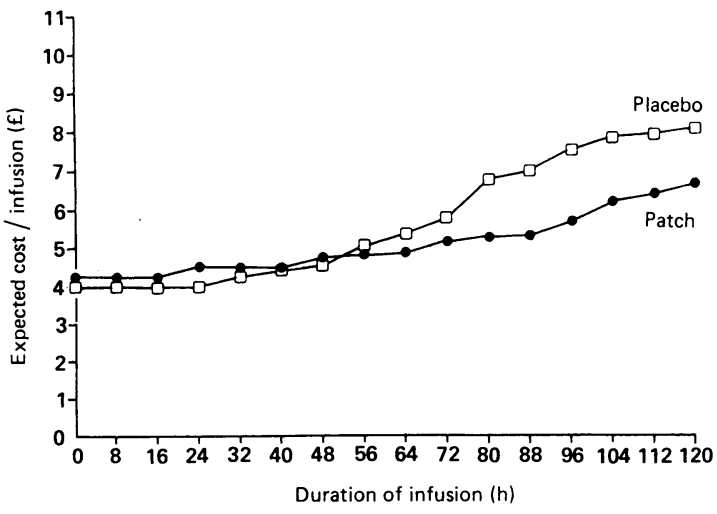

medical and nursing time entailed was estimated from a prospective sample of infusions in a general surgical ward. All costs were at $1987-8$ prices.

The costs were: $\mathrm{C}_{1}=$ cost of first infusion in patients with glyceryl trinitrate patch $=£ 4.27 ; \mathrm{C}_{2}=$ cost of first infusion in patients with placebo patch $=£ 4.00 ; \mathrm{C}_{3}=$ cost of reinfusion (glyceryl trinitrate patch) $=£ 4.51$; $\mathrm{C}_{4}=$ cost of reinfusion $($ placebo patch $)=£ 4.24 ; \mathrm{C}_{5}(\mathrm{t})=$ cost of changing glyceryl trinitrate patch daily (at $27 p$ per patch); $\mathrm{p}_{\mathrm{t}}, \mathrm{q}_{\mathrm{t}}=$ probability of failure of infusion at time $t$ (in treated $(p)$ and control (q) patients), where $0 \leqslant \mathrm{p}_{\mathrm{t}}, \mathrm{q}_{\mathrm{t}} \leqslant 1$.

The cost of reinfusion exceeded that of the first infusion because it included the time taken to dispose of used materials. The expected cost per infusion to time $t$ was therefore $\mathrm{C}_{1}+\mathrm{C}_{5}(\mathrm{t})+\mathrm{p}_{\mathrm{t}} \mathrm{C}_{3}$ in the treatment group and $\mathrm{C}_{2}+\mathrm{q}_{\mathrm{t}} \mathrm{C}_{4}$ in the control group.

For short term infusions ( 24 hours) the expected cost per infusion in the treatment group (£4.54) exceeded that in the control group $(£ 4.03)$ because the early rate of failure was small. For longer infusions (for example, 96 hours), however, the expected cost was lower in the treatment group ( $£ 5.77 v £ 7.60$ ). The cost was equivalent in the treatment and control groups at 48 hours (figure).

\section{Comment}

We found that the net impact on hospital resources of using glyceryl trinitrate patches depended on the duration of the infusion. Using the patches with infusions lasting longer than 48 hours was likely to generate savings; thus the patches should be considered when the infusion time is likely to exceed this threshold. For every 1000 infusions in place for 96 hours the total savings from using the patches would be $£ 1830$. Of this, $£ 950$ is the value of staff time released for other purposes and $£ 880$ the savings on consumables such as cannulas and infusion fluids after allowing for the cost of the patches.

Further studies that explore the benefits to patients of avoiding sequential infusion failure and analyse the costs that are incurred ${ }^{5}$ would be valuable.

\footnotetext{
We thank Ciba-Geigy Pharmaceuticals for supporting this study.

1 Arnold RE, Elliott EK, Holmes BH. The importance of frequent examination of infusion sites in preventing postinfusion phlebitis. Surg Gynecol Obstet of infusion sites

Thomas ET, Evers W, Racz GB. Postinfusion phlebitis. Anesth Analg 1970;49:150-9.

3 Wright A, Hecker JF, Lavis GBH. Use of transdermal glyceryl trinitrate to reduce failure of intravenous infusion due to phlebitis and extravasation. Lancet 1985;ii:1148-50

4 Khawaja HT, Campbell MJ, Weaver PC. Effect of transdermal glyceryl trinitrate on the survival of peripheral intravenous infusions: a double-blind prospective clinical study. Br F Surg 1988;75:1212-5.

5 Drummond MF, Stoddart GL, Torrance GW. Methods for the economic evaluation of health care programmes. Oxford: Oxford University Press, 1987.

(Accepted 29 March 1989)
} 